\title{
PROSA FIKSI REALISTIK \\ DALAM MENUMBUHKAN KARAKTER SISWA
}

\section{Risma Khairun Nisya, M.Pd.}

Universitas Majalengka

Post-el: rismakhairunnisya@gmail.com

\begin{abstract}
ABSTRAK
Menyiapkan generasi penerus bangsa dengan karakter yang kuat menjadi sangat penting pada abad ini.Karakter yang kita kenal sebagai sifat atau watak individu pada perkembangannya dapat dibentuk melalui proses pendidikan.Pendidikan tidak hanya ilmu pengetahuan tetapi moral baik dan buruk yang perlu diketahui oleh siswa.Dalam pembelajaran bahasa Indonesia di Sekolah Dasar, prosa fiksi merupakan salah satu jenis sastra yang terintegrasi dengan mata pelajaran bahasa Indonesia.Dalam hal ini prosa fiksi dapat menjadi media penyampai pesan moral kepada siswa, melalui karakter tokoh-tokohnya.Menumbuhkan karakter siswa melalui literasi sastra di sekolah perlu dikembangkan dengan menyediakan sarana baca yang dapat menarik minat siswa.Prosa fiksi realistik merupakan salah satu media literasi sastra.Cerita yang termasuk jenis prosa fiksi realistik ini bertujuan untuk menyampaikan pesan yang mengandung niainilai kehidupan yang logis, berkaitan dengan etika, moral, religius dan nilai-nilai lainnya.Oleh karena itu, prosa fiksi realistik dapat menjadi salah satu referensi bahan bacaan siswa di Sekolah sebagai sumber pendidikan karakter.Melalui bacaan ini siswa dapat belajar mengenai etika, moral dan kehidupan keagamaan dengan lebih real.
\end{abstract}

Kata kunci : prosa fiksi, realistik, karakter.

\section{PENDAHULUAN}

Pembelajaran dan sastra merupakan dua hal yang tidak dapat dipisahkan karena sastra dalam pembelajaran bahasa Indonesia dapat menjadi sumber pendidikan karakter. Sastra adalah karya lisan atau tulisan yang memiliki berbagai ciri keunggulan seperti keorisinilan, keartistikan, keindahan dalam isi, dan ungkapannya. Sesuai dengan pengertian sastra "Sastra adalah karya tulis yang bila dibandingkan dengan tulisan lain memiliki 
ciri-ciri keunggulan, seperti keaslian, keartistikan, keindahan dalam isi dan ungkapannya.”

Semi (2012:71) menyatakan bahwa “Sebuah karya sastra yang bernilai tinggi adalah karya sastra yang mengandung moral yang tinggi, yang dapat mengangkat harkat martabat

umat manusia.”Berdasarkan hal tersebut maka karya sastra dapat menjadi sarana dalam menyampaikan pesan-pesan moral kepada pembaca.

Sastra terdiri dari prosa, puisi dan drama.Prosa dalam sastra merupakan karya naratif yang bersifat rekaan, kejadian dalam prosa tidak benar-benar terjadi di dunia nyata.Tokoh maupun latar bersifat imajner atau hasil imajinasi pengarang.Jenis kedua yaitu puisi, puisi adalah bentuk karya sastra yang indah dan penuh makna.Puisi terikat oleh irama dan rima.Sedangkan drama adalah seni cerita melalui percakapan dan akting tokoh.Ketiga jenis sastra tersebut terintegrasi pada keempat keterampilan berbahasa, yaitu menyimak, berbicara, membaca, dan menulis.Hal ini bertujuan agar siswa mampu mengapresiasi karya sastra serta memahami nilai-nilai kehidupan yang digambarkan melalui karakter/watak tokoh dalam cerita.
Prosa terdiri dari prosa fiksi dan nonfiksi.Prosa fiksi disebut juga sebagai cerita rekaan yang kebenarannya tidak dapat dibuktikan dalam dunia nyata.Sedangkan dalam prosa nonfiksi, cerita bersifat faktual dan tokoh, peristiwa, atau latar dapat dibuktikan di dunia nyata secara empiris.Adapun yang dimaksud dengan prosa fiksi realistik merupakan cerita fiksi yang menyampaikan nilai-nilai kehidupan yang bersifat logis seperti etika, sikap religi dan nilai-nilai moral.Realistik itu sendiri merujuk pada kehidupan sehari-hari yang diangkat dalam cerita fiksi tersebut sehingga dapat menjadi contoh bagi pembacanya.

Penulis dalam makalah ini membahas mengenai menumbuhkan karakter siswa melalui prosa fiksi realtistik.Karakter adalah sikap dasar yang dimiliki setiap individu.Karakter sangat penting untuk selalu diintegrasikan dalam pembelajaran.Hal ini bertujuan bahwa pembelajaran tidak hanya mentransfer ilmu pengetahuan tetapi juga membentuk karakter individu. Seperti yang tercantum dalam tujuan pendidikan Nasional yaitu mencerdaskan kehidupan bangsa dan mengembangkan manusia Indonesia seutuhnya, yaitu manusia yang beriman dan bertakwa terhadap Tuhan Yang Maha 
FON ; Jurnal Pendidikan Bahasa dan Sastra Indonesia

Volume 13 Nomor 2 Tahun 2018

Esa dan berbudi pekerti luhur, memiliki

bacaan siswa di Sekolah.Berdasarkan pengetahuan dan keterampilan, kesehatan jasmani dan rohani, kepribadian yang mantap dan mandiri serta rasa tanggung jawab kemasyarakatan dan kebangsaan.

pemaparan tersebut, penulis merumuskannya dalam judul makalah "Prosa Fiksi Realistik dalam Menumbuhkan Karakter Siswa.”

Tujuan pendidikan Nasional tersebut pada dasarnya adalah untuk menyiapkan generasi penerus bangsa yang tidak hanya cerdas tetapi berakhlak mulia, memiliki kepribadian mantap serta memiliki kecintaan pada bangsa dan negaranya.Adapun karakter yang tercantum dalam Kementerian Pendidikan Nasional Badan Penelitian Dan Pengembangan Pusat Kurikulum (2010:16), meliputi delapan belas poin, diantaranya: religi, jujur, toleransi, disiplin, kerja keras, kreatif, mandiri, demokratis, rasa ingin tahu, semangat kebangsaan, cinta tanah air, menghargai prestasi, bersahabat/komunikatif, cinta damai, gemar membaca, peduli lingkungan, sikap peduli sosial, dan bertanggung jawab.

Literasi sastra di sekolah dengan prosa fiksi realistik tidak hanya mengajarkan siswa untuk mengapresiasi karya sastra tetapi lebih utama adalah menumbuhkan karakter siswa melaluisikap positif dari tokoh cerita.Oleh karena itu, dalam hal ini guru perlu memilih prosa yang sesuai sebagai bahan

\section{II.} Burhan, (2004:109) menyatakan bahwa "Cerita anak dapat berkisah tentang apa saja yang menyangkut masalah kehidupan ini sehingga mampu memberikan informasi dan pemahaman yang lebih baik tentang kehidupan. Sedangkan Huck, dkk (1987:6) menekankan bahwa "Buku anak, sastra anak adalah buku yang menempatkan sudut pandang anak sebagai pusat penceritaan." Selanjutnya Winch (1991:19) mengatakan bahwa "Buku anak yang baik adalah buku yang mengantarkan dan berangkat dari kacamata anak. Berdasarkan pendapat tersebut, dapat disimpulkan bahwa dalam menyajikan cerita anak kepada siswa di sekolah, dapat berupa cerita anak apa saja yang memberikan informasi sesuai dengan jangkauan pemahaman anak. Prosa fiksi realistik dapat menjadi salah satu pilihan media literasi sastra di sekolah.

Cerita yang termasuk dalam jenis prosa fiksi realistik adalah cerita yang logis mengenai etika, moral dan 
religi.Realisme dalam sastra menurut dan interaksi yang seolah-olah memang Burhan, dapat dipahami bahwa "Cerita benar-benar terjadi berkaitan dengan yang dikisahkan itu mungkin saja ada dan etika, moral dan sikap religi terjadi walaupun tidak harus bahwa ia tokohnya.Penulis memberikan beberapa memang benar-benar ada dan terjadi." referensi bahan bacaan untuk siswa Selanjutnya Burhan mengatakan bahwa Sekolah Dasarkelas rendah dan Sekolah "Peristiwa yang dikisahkan masuk akal Dasar kelas tinggi.Sekolah Dasar kelas dan logis. Cerita mempresentasikan rendah yaitu buku berjudul "Little berbagai peristiwa, aksi dan interaksi, Abid"dan untuk siswa Sekolah Dasar yang seolah-olah memang benar, dan kelas tinggi yaitu buku cerita anak penyelesaiannya pun masuk akal dan berjudul "Balada Sepeda Butut". Dalam dapat dipercaya."

Penulis menyimpulkan bahwa prosa buku anak Little Abidterdiri dari empat seri yaitu basic knowledge, life skill, fiksi realistik yang menjadi bacaan anak di general values, spiritual sekolah adalah prosa fiksi yang values.Seluruhnya terdiri dari 27 buku, mengisahkan peristiwa yang masuk akal yang dirangkum dalam tabel berikut. dan logis dengan berbagai peristiwa, aksi

\begin{tabular}{|c|c|c|c|c|}
\hline No. & basic knowledge, & life skill, & general values & $\begin{array}{c}\text { spiritual } \\
\text { values }\end{array}$ \\
\hline 1. & $\begin{array}{l}\text { I Learn About } \\
\text { Talking to Others }\end{array}$ & $\begin{array}{ll}\text { Aku Tahu } & \text { Dari } \\
\text { Mana } & \text { Aku } \\
\text { Berasal } & \end{array}$ & Jujur Itu Hebat & $\begin{array}{l}\text { Allah } \\
\text { Mahahebat }\end{array}$ \\
\hline 2. & I Learn About Time & $\begin{array}{l}\text { Aku Tahu Hari } \\
\text { dan Bulan }\end{array}$ & $\begin{array}{l}\text { Aku } \\
\text { Menghargai } \\
\text { Perbedaan }\end{array}$ & $\begin{array}{l}\text { Rasalullah } \\
\text { Idolaku }\end{array}$ \\
\hline 3. & $\begin{array}{l}\text { I Learn About } \\
\text { Moving Around }\end{array}$ & $\begin{array}{ll}\text { Aku } & \text { Mandi } \\
\text { Sendiri } & \end{array}$ & $\begin{array}{ll}\text { Aku } & \text { Suka } \\
\text { Berbagi } & \end{array}$ & $\begin{array}{ll}\text { Aku Rajin } \\
\text { Shalat }\end{array}$ \\
\hline 4. & $\begin{array}{l}\text { I Learn About } \\
\text { Sounds }\end{array}$ & $\begin{array}{l}\text { Aku Makan } \\
\text { Makanan Sehat }\end{array}$ & $\begin{array}{l}\text { Aku Sayang } \\
\text { Ayah Bunda }\end{array}$ & $\begin{array}{l}\text { Aku Rajin } \\
\text { Mengaji }\end{array}$ \\
\hline
\end{tabular}


FON ; Jurnal Pendidikan Bahasa dan Sastra Indonesia Volume 13 Nomor 2 Tahun 2018

\begin{tabular}{|l|l|l|l|l|}
\hline 5. & $\begin{array}{l}\text { I Learn About } \\
\text { Texture }\end{array}$ & Gigiku Sehat & $\begin{array}{l}\text { Aku Anak } \\
\text { Penyayang }\end{array}$ & \\
\hline 6. & $\begin{array}{l}\text { I Learn About Taste } \\
\text { and Smell }\end{array}$ & $\begin{array}{l}\text { Aku Berani } \\
\text { Tidur Sendiri }\end{array}$ & $\begin{array}{l}\text { Aku Berbeda } \\
\text { Dengan Syafa }\end{array}$ & \\
\hline 7. & $\begin{array}{l}\text { I Learn About } \\
\text { Colours }\end{array}$ & $\begin{array}{l}\text { Aku Belajar } \\
\text { Pertolongan } \\
\text { Pertama Aku Banga }\end{array}$ & $\begin{array}{l}\text { Pada Mereka } \\
\text { Para }\end{array}$ & \\
\hline 8. & I Learn About Math & $\begin{array}{l}\text { Aku Anak } \\
\text { Percaya Diri }\end{array}$ & \\
\hline
\end{tabular}

Buku Little Abid cocok dibaca untuk siswa Sekolah Dasar kelas rendah karena memberikan pengetahuan dan moral kepada anak yang dikemas dalam cerita “Abid” dengan bahasa yang mudah dipahami. Selain dari itu, moral dan sikap religi yang disampaikan dalam little Abid mengangkat tema kehidupan sehari-hari sehingga berada dalam jangkauan pemahaman anak. Sebagai contoh buku berjudul “Aku Bangga pada Mereka” membahas tentang bagaimana anak menghargai semua profesi yang ada dan gambaran cita-cita mereka nanti akan menjadi apa. Buku berjudul “Jujur Itu Hebat” membahas tentang bekerja sama dalam kelompok, bertanggung jawab terhadap tugas yang diberikan, jujur lebih baik dan ketidakjujuran akan merusak persahabatan. Buku berjudul "Aku
Menghargai Perbedaan” membahas khusus bab toleransi, bagaimana anakanak agar menghargai perbedaan agama, warna kulit, kondisi fisik, dll. Buku berjudul “Aku Belajar Pertolongan Pertama" membahas tentang pertolongan pertama pada kecelakaan.Buku berjudul “Aku Berbeda dengan Syafa” membahas mengenai mengenalkan bahwa Allah menciptakan hanya ada laki-laki dan perempuan, memahami perbedaan antara laki-laki dan perempuan.

Cerita anak berjudul "Balada Sepeda Butut” menceritakan seseorang bernama Lina memiliki sebuah sepeda kesayangan yang ia dapatkan sebagai hadiah ulang tahunnya yang ketujuh dari almarhum ayahnya. Meskipun sepeda itu sudah butut, Lina tetap menjaganya.Sepeda itu menyimpan kenangan indah tentang 
almarhum ayahnya.Suatu hari Lina dibuat mengangkat kehidupan sehari-hari kalang kabut.Ia kehilangan sepedanya. sehingga memudahkan siswa dalam Lina sedih harus kehilangan sepeda butut memahami pesan moral yang terdapat yang memiliki nilai sejarah dan kenangan dalam cerita.Dari kedua jenis cerita anak yang sangat berharga.Ia dan ibunya tidak yang dipaparkan dalam pembahasan, mampu membeli sepeda baru. Lina keduanya termasuk dalam jenis prosa fiksi berusaha dengan tekun dan ikhlas realistik karena baik "little Abid" maupun mengumpulkan uang untuk memiliki "Balada Sepeda Butut”, menceritakan sepeda baru.Lina beruntung memiliki kehidupan sehari-hari, logis, mengandung banyak teman yang membantu nilai-nilai pendidikan, etika, moral, dan mewujudkan impiannya untuk memiliki sikap religi tokoh-tokohnya.Melalui prosa sepeda baru.

Cerita tersebut bertema kehidupan sehari-hari seorang anak yang memiliki sepeda pemberian ayahnya.Kehidupan sederhana dan kerja keras Lina dapat menjadi contoh siswa bahwa mendapatkan sesuatu memerlukan usaha dan kerja keras.Selain dari itu, persahabatan dan saling membantu sesama teman memupuk karakter bersahabat dan peduli sosial.

\section{SIMPULAN DAN SARAN}

Media literasi sastra melalui prosa fiksi realistik membantu siswa tidak hanya mengapresiasi karya sastra tetapi belajar mengenai etika, moral dan kehidupan religi.Etika, moral dan kehidupan religi merupakan bagian dari karakter, melalui fiksi realistik sebagai media literasi sastra di sekolah, siswa dapat memperoleh pendidikan karakter melalui bahan bacaan.

Saran yang dapat penulis sampaikan, kita sebagai guru, sebagai orang tua yang telah lebih dahulu tau dan dapat membedakan moral baik dan buruk, perlu terus memberikan bimbingan dan arahan kepada anak baik secara langsung maupun tidak langsung. Bimbingan secara tidak langsung salah satunya melalui bacaan anak yang sesuai dengan tingkat perkembangan psikologisnya. Sastra sebagai sumber pendidikan karakter, oleh karena itu melalui sastra diharapkan dapat membentuk karakter siswa sebagai pembacanya.

bacaan ini siswa dapat mempelajari nilainilai kehidupan yang dikemas dalam bacaan.Realistik dalam cerita anak 
FON ; Jurnal Pendidikan Bahasa dan Sastra Indonesia

Volume 13 Nomor 2 Tahun 2018

DAFTAR PUSTAKA

Aminuddin. 2001. Pengantar Apresiasi

Sastra. Yogyakarta: Sinar Baru.

Doni Koesoema A. (2007). Pendidikan

Karakter: Strategi Mendidik Anak di

Zaman Global. Jakarta: Grasindo.

Cet. I.

Griya Wardani. Nilai-nilai Pendidikan.

Dalam http//Wordpress.com

Nurgiyantoro, Burhan. 2004. Sastra Anak:

Persoalan Genre. Jurnal Humaniora

Vol 16, No 2

Nurgiyantoro, Burhan. 2012. Teori

Pengkajian Fiksi. Yogyakarta:

Gadjah Mada University Press.

Priyatni, Endah Tri. 2015. Membaca

Sastra dengan Ancangan Literasi

Kritis.Jakarta: Bumi Aksara.
Ruswandi, Uus (dkk). 2009. Landasan

Pendidikan. Bandung: CV Insan

Mandiri.

Sadikin, Mustofa. 2011. Kumpulan Sastra Indonesia.Jakarta: Gudang Ilmu.

Saryono, Djoko. 2009. Dasar Apresiasi

Sastra. Yogyakarta: Elmatera

Publishing.

Susilo, Bambang Joko. 2012. Balada

Sepeda Butut. Jakarta: Bestari Kids

Wiyanto, Asul. 2005. Kesusastraan

Sekolah. Jakarta: Gramedia

Widiasarana Indonesia. 